\title{
The Potential Anti-Inflammatory Effect of Exercise in Chronic Obstructive Pulmonary Disease
}

\author{
Jantine van der Vlist ${ }^{a}$ Thomas W.J. Janssen ${ }^{\mathrm{a}, \mathrm{b}}$

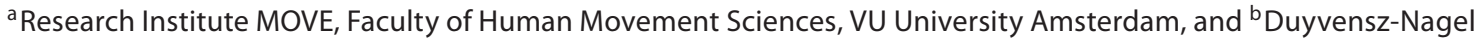 \\ Research Laboratory, Rehabilitation Center Amsterdam, Amsterdam, The Netherlands
}

\section{Key Words}

Chronic obstructive pulmonary disease $\cdot$ Exercise training $\cdot$

Tumor necrosis factor- $\alpha \cdot$ Interleukins $\cdot$ Cytokines

\begin{abstract}
People with chronic obstructive pulmonary disease (COPD) suffer from muscle dysfunction which seems to be partly caused by systemic inflammation. Muscle protein breakdown as well as synthesis might be affected by this systemic inflammation. Additionally, it seems to induce excessive oxidative stress and reduce the level of growth-stimulating factors. As exercise training can have an anti-inflammatory effect in healthy people, the main question in this review is whether exercise (training) can also induce such effects in patients with COPD. However, because of the known inflammatory response after an acute bout of exercise, some researchers are afraid that exercise might actually worsen the inflammation in COPD. Recent evidence suggests, however, that the response might actually be anti-inflammatory and thus beneficial. Unfortunately, the evidence about the response of the inflammatory cytokines tumor necrosis factor$\alpha$ and interleukin- 6 to exercise in patients with COPD is inconsistent, making it impossible to conclude whether a single exercise bout is harmful or beneficial in patients with COPD. Long-term exercise training in healthy people as well as in patients with chronic heart failure, another chronic in-
\end{abstract}

flammatory disease, seems to have beneficial effects on the inflammatory response. In patients with COPD, however, no training-induced changes in cytokine levels have been found and it must be concluded that physical exercise training does not seem to have an anti-inflammatory effect in COPD. On the other hand, it does not have a proinflammatory effect, and since patients with COPD benefit from exercise training with regard to other health parameters it is still recommended that they exercise regularly.

Copyright $\odot 2009$ S. Karger AG, Basel

\section{Introduction}

Patients with chronic obstructive pulmonary disease (COPD) suffer from irreversible and mostly progressive airway limitation caused by inflammation of the airways, lung parenchyma and pulmonary vasculature as a reaction to noxious gases such as cigarette smoke. In recent decades, COPD has become a leading global disease with a prevalence of over $10 \%$ worldwide [1]. Prognoses are even worse because of the increasing pollution of the environment.

In advanced stages, COPD is characterized by dyspnea, cough and excessive mucus production. These characteristics reduce the level of daily physical activity of people with COPD and consequently have a great im-

Thomas W.J. Janssen, PhD, FACSM

Faculty of Human Movement Sciences

VU University Amsterdam, Van der Boechorststraat 9

NL-1081BT Amsterdam (The Netherlands)

Tel. +31 20598 8586, Fax +31 20598 8529, E-Mail t.janssen@fbw.vu.nl 
pact on their quality of life [2]. Many patients develop a sedentary lifestyle, which reduces their exercise capacity even more. The exercise capacity in patients with COPD seems indeed reduced, as they only produce $60 \%$ of the predicted power output during maximal exercise [3]. Airflow limitation as the only limiting factor during exercise, however, was first doubted by Killian et al. [3]. They found that in COPD, the limiting factor is mostly leg fatigue and not, as expected, dyspnea. Apparently, besides respiratory function, skeletal muscle function is also a fundamental factor in exercise capacity in COPD.

Since muscle weakness has been linked to patient survival, exercise training has been developed as a rehabilitation therapy $[4,5]$. As in healthy subjects, exercise training has been proven to improve the changes associated with disuse in the muscles of people with COPD, i.e. loss of muscle mass, decrease in cross-sectional area and a fiber-type shift $[6,7]$.

However, it was recently found that patients with COPD not only suffer from disuse atrophy, but also from muscle dysfunction, such as mitochondrial abnormalities and excessive oxidative stress [8-10]. This dysfunction seems to be partly caused by systemic inflammation, a pathogenic characteristic of COPD. The inflammatory mediators seem to affect the regulation of muscle protein and consequently impair muscle function. To reduce these inflammatory chemicals, many people with COPD use corticosteroids. Unfortunately, this medicine has several negative side effects and in addition seems to contribute to muscle weakness in COPD [11]. Therefore, the interesting question arises whether there are alternative treatments that diminish the amount of circulating inflammatory factors without those side effects. Physical training might be such an alternative treatment, because besides the probable improvements in muscle strength, recent research has indicated that it diminishes inflammation as well.

In this review, this issue will be clarified. The muscular dysfunction and inflammatory response in patients with COPD will be discussed, after which the effects of physical training on the inflammatory response will be evaluated.

\section{Peripheral Muscle Dysfunction in COPD}

The peripheral muscle dysfunction in people with COPD was long neglected, but has received more attention during the last decade. It is now clear that the strength (by $20-31 \%[6,11-13]$ ) and endurance (by $>50 \%$ [14]) of the knee extensor muscles are impaired in COPD patients. Hence, there is currently an interesting debate about the underlying mechanisms of these impairments and muscle dysfunction. Concerning this discussion, it is important to keep in mind that muscle dysfunction can be divided into 2 components. Firstly, there is the loss of muscle mass (atrophy), and secondly, there is the malfunction of the remaining muscle tissue. It was initially thought that the first component, atrophy, accounted for all the loss in muscle strength. This is not a strange idea, because people with COPD obviously lose body mass as a result of a relatively great loss of muscle mass, evidenced by reductions in fat-free mass and muscle cross-sectional area [15]. For example, the cross-sectional area of the calf muscle is substantially smaller in COPD patients than in healthy controls (60 vs. $74 \mathrm{~cm}^{2}$ ) [16]. Moreover, this first idea was supported by Bernard et al. [6], who found that this reduction in cross-sectional area was of the same magnitude as the reduction in muscle strength. This indicates that atrophy rather than functional defects of the muscles is an important determinant of the loss in muscle strength.

However, the latest research results suggest that besides atrophy, dysfunction of the remaining muscle also contributes to the loss in muscle function in COPD. For instance, a structural shift in muscle fiber type from the slow oxidative type 1 fibers to the fast glycolytic type 2 fibers has been demonstrated $[15,17,18]$. Consequently, the muscles become less oxidative, leading to a loss in fatigue resistance [19]. Because of this change in oxidative capacity, it can be assumed that there are also metabolic alterations. Research has indeed shown reduced activity of aerobic enzymes and increased activity of glycolytic enzymes in the muscles of people with COPD [16, 20]. These changes are associated with an early increase in intracellular acidosis occurring at much lower work rates compared to healthy subjects [16]. Another indicator for impaired oxidative muscle metabolism in COPD is the slow phosphocreatine resynthesis rate at the end of exercise, which is closely related to adenosine triphosphate resynthesis and thus energy restoration [16, 17, 21]. Moreover, besides the limited oxygen uptake, delivery of oxygen to the peripheral muscles also seems to be impaired, probably as a result of reduced capillarity and low levels of myoglobin, which has a key role in the transport and storage of oxygen [22].

In conclusion, it seems clear that the muscles of people with COPD do not function appropriately. Yet, the question remains as to what mechanisms are responsible, i.e. disuse or a possible myopathological mechanism. 
The above-mentioned symptoms of muscle dysfunction seem to be partly caused by the sedentary lifestyle of people with COPD and consequently the disuse of their peripheral muscles. However, recent findings suggest that some of the changes in the muscles might also be attributable to a pathological state of the muscle. Although it might be difficult to distinguish between pathological changes and changes related to disuse, it would be interesting to explore the possible myopathological mechanisms underlying this muscle dysfunction, as this could provide greater insight into the process of the disease. Some such mechanisms have been pointed out in recent studies.

For example, hypoxia seems to induce some of the changes seen in the muscles of people with COPD. Similar changes are seen in healthy subjects exposed to high altitude, such as decreased muscle mass and number of mitochondria and increased activity of glycolytic enzymes versus decreased activity of oxidative enzymes [23, 24]. However, not all the changes seem to be caused by hypoxia, since people with COPD benefit only in part from oxygen supplementation, which should neutralize the hypoxia [25]. So, other potential underlying mechanisms have been suggested. Nutritional depletion, for instance, is another factor that might contribute to muscular dysfunction. Low protein intake combined with high energy expenditure can lead to an imbalance in catabolism and anabolism which causes muscle wasting. However, there is no consensus in the literature regarding this imbalance and as yet no effects of nutritional interventions have been found [4].

Recently, inflammation has been associated with the observed metabolic changes seen in COPD. Inflammation is a characteristic of COPD and it seems to provoke oxidative stress and muscle protein degradation $[26,27]$. In COPD, but also in other chronic wasting diseases, such as chronic heart failure (CHF) and cancer, inflammation may contribute to impaired exercise capacity [28-30]. Furthermore, there is some evidence for a positive effect of exercise training on the inflammatory response in people with CHF and in healthy subjects [29, 31]. For rehabilitation practice, it would be of great significance if the effects of inflammation on exercise capacity and muscle function in COPD were elucidated. Moreover, a breakthrough might be realized when it becomes clear whether exercise can diminish the systemic inflammatory response in COPD. In the following sections, we give an overview of the findings with regard to inflammation and exercise and suggestions for possible rehabilitation programs.

\section{Systemic Inflammation and Muscle Dysfunction in COPD}

It is widely recognized and accepted that people with COPD suffer from chronic inflammation of the lungs. This inflammation is characterized by infiltration of mononuclear immune cells, such as macrophages and lymphocytes. Accumulation of these cells may obstruct the airways of people with COPD, which can lead to the typical signs of COPD, such as dyspnea. Besides this generally accepted pathology of COPD, however, people with COPD also seem to suffer from systemic inflammation, involving the whole body, including peripheral muscle [32]. This is characterized by increased circulating levels of inflammatory cells and it induces systemic oxidative stress $[8,33,34]$.

Furthermore, recent findings indicate that systemic inflammation is associated with abnormal body composition and muscle dysfunction $[35,36]$. For example, serum levels of the inflammatory cytokine [37] tumor necrosis factor (TNF)- $\alpha$ seem to be higher in COPD patients with reduced body mass, body mass index and fat-free mass $[35,36,38]$. Although these reductions could be a result of a loss of muscle mass, other causes cannot be ruled out. Eid et al. [38] tried to solve this problem by examination of the relationship between TNF- $\alpha$ and the creatine height index $(\mathrm{CHI})$, which reflects net muscle mass. In their study, subjects were placed in 1 of 2 groups based on $\mathrm{CHI}$, i.e. a muscle-depleted group (CHI $<80 \%$ predicted) and a muscle replete group (CHI $>80 \%$ predicted). The level of circulating TNF- $\alpha$ was significantly higher in the muscle-depleted group than in the muscle replete group, indicating that TNF- $\alpha$ does indeed affect muscle mass. More specific research by Yende et al. [30] indicated that high levels of systemic TNF- $\alpha$ are associated with low quadriceps strength. This was also true for IL-6, another inflammatory cy tokine. However, although there seems to be a link between inflammatory cy tokines and muscle wasting, not all studies have been able to show this [30]. Moreover, because of the cross-sectional design of the above-mentioned studies, the temporal relationships and the exact roles of the inflammatory markers are as yet unknown. Fortunately, although we are still far from complete understanding, much progress has been made in recent decades with the help of animal experiments. These experiments indicate that inflammatory mediators are (partly) responsible for the imbalance between protein degradation and synthesis. Because human research on this topic is scarce, these animal experiments are very valuable. However, one should be cau- 
tious with the translation from animal experiments to the human situation since there might be major differences between animals and humans with regard to several characteristics. In the following sections, the results of animal experiments and the different possible mechanisms are discussed.

\section{Protein Degradation}

Increased protein degradation activated by inflammatory factors seems to be partly responsible for the muscle wasting in COPD. TNF- $\alpha$, a cytokine produced by tissue macrophages and blood monocytes, is an important factor that seems to be involved in this degradation, and its role has been investigated in several animal experiments. The first studies concentrated on the causal relationship between TNF- $\alpha$ and muscle mass. For example, one study found a significant loss of gastrocnemius mass in rats injected with TNF- $\alpha$ compared to control animals [39], which could have been a result of protein degradation initiated by TNF- $\alpha$; however, because TNF- $\alpha$ suppresses food intake, it might also have been due to starvation. However, because the mass of the gastrocnemius muscle in an additional control group of rats that ate the same (small) amount of food as those injected with TNF- $\alpha$ was relatively spared compared to the TNF- $\alpha$ group, it was concluded that TNF- $\alpha$ can change body protein distribution, perhaps as a result of increased degradation.

To analyze whether TNF- $\alpha$ does indeed have any direct effects on muscle protein degradation, early experiments incubated muscles removed from rodents with TNF- $\alpha$ in vitro. For instance, Moldawer et al. [40] injected the extensor digitorum longus (EDL) muscle of mice with TNF- $\alpha$ and measured the amount of tryosine released, which is commonly used as an estimation of the protein degradation rate. However, they could not find an effect of pure TNF- $\alpha$ on the degradation rate (even a 10-fold higher dose did not change the results), and it was concluded that TNF- $\alpha$, on its own, is not responsible for protein degradation. Similarly, Kettelhut and Goldberg [41] found no changes in tryosine in either the soleus muscle or the EDL muscle of rats after $4 \mathrm{~h}$ of incubation with TNF- $\alpha$. These early in vitro findings lead to the conclusion that TNF- $\alpha$ has no direct effect on protein loss.

However, the lack of effect in these studies might be due to the short incubation times $(2-4 \mathrm{~h})$. Indeed, cachexia is only seen after 2 weeks [42], and it seems reasonable that degradation might also start only after prolonged exposure to TNF- $\alpha$. Recently, studies that applied longer incubation times indicated that TNF- $\alpha$ directly induces a time- and concentration-dependent loss of muscle protein [43].

Another point that might have influenced the results of early in vitro studies is that TNF- $\alpha$ probably needs other cytokines as mediators and by itself is not able to cause protein degradation [44]. This suggestion was already supported by the results of Moldawer et al. [40] in 1987. While they did not find an effect of pure TNF- $\alpha$ on the protein degradation rate, they did find an increase in protein degradation as a result of infusion of activated mononuclear cells, which also produce other cytokines besides TNF- $\alpha$. So it appears that there is (also) another product of monocytes that contributes to muscle protein degradation. Interleukin (IL)-1 might be such a mediator, since Flores et al. [45] found that a cytokine mixture of TNF- $\alpha$ and IL-1 was significantly more strongly associated with muscle protein loss than TNF- $\alpha$ alone.

So, although challenged by some early studies, it can be stated that (a combination of) inflammatory cytokines seem to mediate muscle degradation in COPD. The exact mechanism of this cytokine effect still needs to be elucidated.

Nonetheless, some evidence indicates that inflammatory cytokines cause protein degradation via the ubiquitin-proteasome pathway $[26,44,46]$. In this pathway, proteins that need to be destroyed are labeled by ubiquitin with a so-called 'ubiquitin kiss of death' and from then on are targets for the proteasomes, which break down unneeded or damaged proteins. Llovera et al. [46] found that expression of the ubiquitin gene in the skeletal muscle of tumor-bearing rats was indeed higher. Whilst at first they were unable to find any direct effects of TNF- $\alpha$ [46], in a more recent study they did find direct effects of the cytokine [26].

Besides the possible direct effects of cytokines on muscle wasting, several studies have suggested that inflammation also contributes to muscle wasting via induction of oxidative stress. Normally, the immune system uses reactive oxygen to kill pathogens, but in the presence of oxidative stress there is too much reactive oxygen, which results in disastrous damage to the host tissue. In COPD it seems that inflammatory cytokines can induce the release of reactive oxygen species (ROS). This was illustrated by Meier et al. [47], who showed that human fibroblasts produce $\mathrm{O}_{2}$ and $\mathrm{H}_{2} \mathrm{O}_{2}$ when stimulated with TNF$\alpha$ and IL-1. In addition, it was found that concentrations of the oxidant nitric oxide synthase (NOS) were significantly higher in mice injected with TNF- $\alpha$ than in controls [48]. Hence, NOS seems to play a mediatory role in oxidative stress in skeletal muscle, which is demonstrated 
Fig. 1. The possible effects of inflammation on muscle protein degradation and synthesis. When TNF- $\alpha$ binds to its receptor, this might induce a cascade of actions that possibly affect muscle protein degradation and synthesis via apoptosis, the release of ROS, ubiquitin activity and reductions in growth hormone receptor sensitivity, which reduces IGF-1 levels, and muscle disuse. TNF-R = TNF receptor; MyoD = myogenic differentiation factor D; Ubq = ubiquitin; GH = growth hormone. This figure was adapted from Sevenoaks and Stockley [62], with permission.

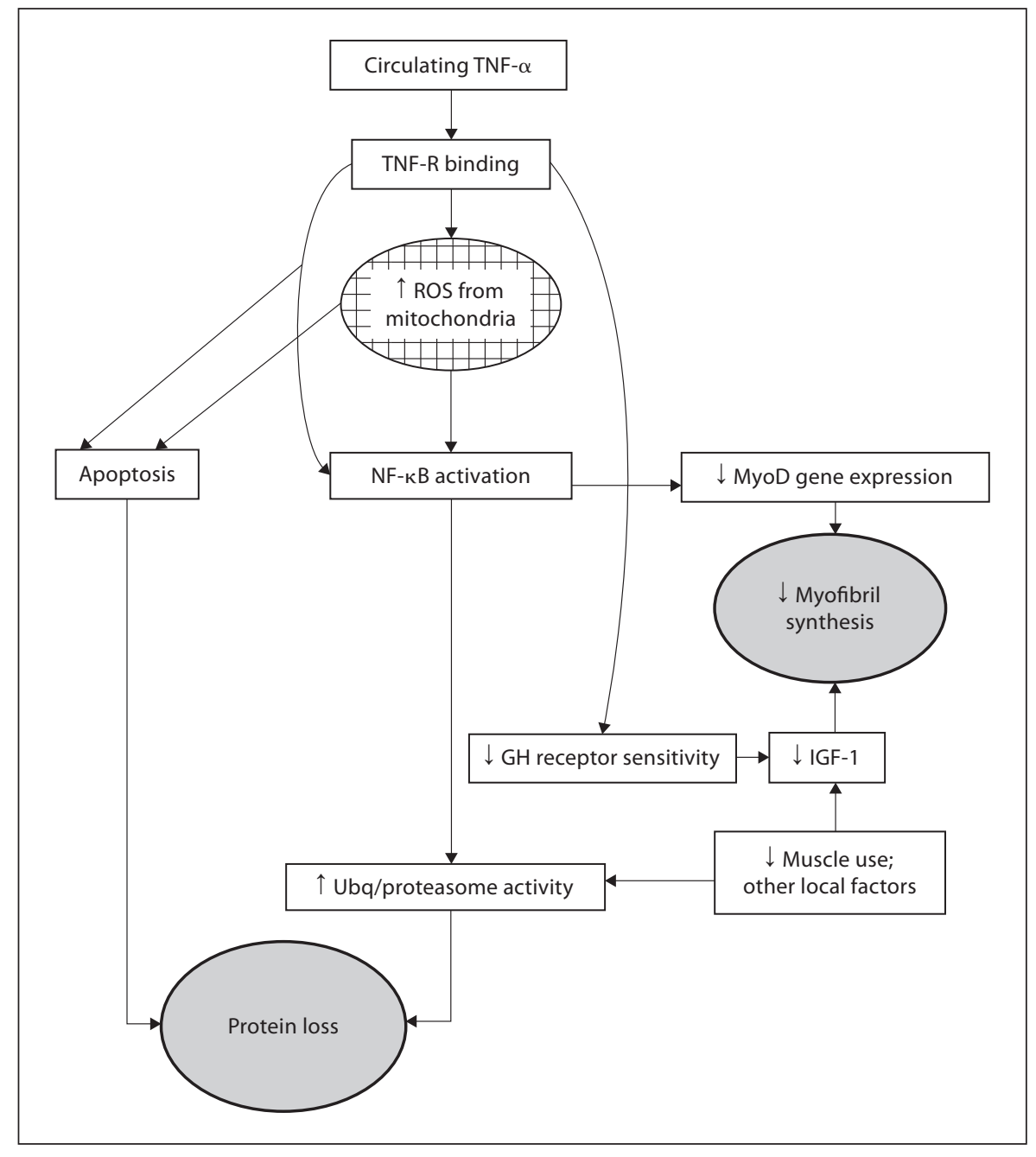

by the finding that when inhibitors of NOS were injected into TNF- $\alpha$-infused mice, the increased expression of NOS was prevented and, more interestingly, so were its effects on muscle wasting [48]. It is important to mention that the inhibitors did not affect the secretion, survival or serum levels of TNF- $\alpha$ and that the discovered effects were thus not a result of diminished TNF- $\alpha$ levels.

In addition to oxidative stress, recently nuclear factor kappa B (NF- $\mathrm{B}$ ) has been implicated as another potentially important mediating factor in the regulation of protein breakdown. In some way, inflammatory cytokines seem to induce activation of the NF- $\kappa$ B pathway, and this activation might cause increased levels of muscle-specific RING finger protein 1, a ligase involved in ubiquitinization. However, the evidence is not very strong, and the NF- $\kappa \mathrm{B}$ pathway needs further examination.
In summary, the ubiquitin/proteasome pathway, oxidative stress and the NF- $\kappa$ B pathway seem to be stimulated by inflammatory cytokines (in particular TNF- $\alpha$ ), which in turn leads to the breakdown of muscle protein (fig. 1). However, the research in this area is scarce, and the exact role of cytokines in these pathways needs further examination. Moreover, the studies described were all animal experiments. It is largely unknown how inflammatory cytokines manifest in humans. Figure 1 is therefore hypothetical and should not be regarded as unambiguous.

\section{Protein Synthesis}

In light of the findings on protein degradation, it seems that the imbalance in protein turnover can be partly explained by increased rates of muscle protein degradation. However, some studies suggest that this imbal- 
ance is intensified by diminished rates of protein synthesis. While in healthy muscles protein is constantly synthesized to compensate for the regular breakdown and to maintain an appropriate muscle mass, this synthesis seems to be affected in COPD. Interestingly, this may be partly caused by inflammatory cytokines.

Decades ago, the first investigators tested the effects of TNF- $\alpha$ on protein synthesis. While these first studies were not able to detect any effects of injected TNF- $\alpha$ or IL-1 on the protein synthesis rate, either in vitro or in vivo $[40,41]$, more recent studies were. For example, Vary et al. [49] found that rats with induced sepsis showed a 55\% decrease in protein synthesis in the gastrocnemius muscle. Sepsis was used to elevate endogenous levels of inflammatory cytokines and was achieved by the administration of a 'fecal agar pellet' which contains bacteria that cause abdominal sepsis. The effect on protein synthesis in the rats was the same with regard to myofibrillar and sarcoplasmic protein, suggesting that sepsis causes a general response, with all proteins being equally affected. Moreover, it was found that administration of the receptor antagonist of the cytokine IL-1 (IL-1ra) completely ameliorated the decreased rates of protein synthesis induced by sepsis $[49,50]$, indicating that IL-1 affects protein synthesis.

However, studies that use sepsis as an intervention might elicit responses other than inflammation alone, as indicated by diminished protein synthesis rates in septic animals but not in animals with nonseptic inflammation [51]. So, findings from studies using sepsis as a model might be misleading and not completely representative of the inflammation seen in COPD. Studies that administered inflammatory cytokines are probably more representative, such as the study of Garcia-Martinez et al. [52], who investigated the effect of TNF- $\alpha$ treatment on the rate of protein synthesis in rats. While the synthesis rate was decreased in the soleus muscle of the rats, no effects were found in the EDL muscle. However, opposing results were recently found, with a more pronounced decrease in the protein synthesis rate in the EDL (31\%) compared to the soleus (14\%) muscle during inflammation [53]. The discrepancy between the 2 investigated muscles might be explained by differences in sensitivity to inflammatory cytokines between the slow-twitch fibers of the soleus muscle and the fast-twitch fibers of the EDL muscle [54, 55]. However, since the results regarding the response of the different muscles to inflammation are contradictory in the above-mentioned studies, no conclusion about these possible differences can be drawn.

Anti-Inflammatory Effect of Exercise
Although there are several indications that inflammation might induce deficiencies in protein synthesis, the responses vary among studies. Unfortunately, these diverse results might be inevitable because of the various hormonal milieus of the hosts, the kind of cytokine (combination) and the method used to induce inflammation, making it difficult to formulate unambiguous statements and reach an absolute consensus on this subject.

Nevertheless, some researchers became interested in the underlying mechanisms of the probably affected regulation. There are several levels at which the regulation of protein synthesis can be affected, i.e. the efficiency of translation of mRNA into useful proteins, the proliferation of satellite cells to form pools of myoblasts or the differentiation of myoblasts to myotubes. This last level, called myogenic differentiation, is the formation of multinucleated muscle fibers from the fusion of myoblasts, the muscle stem cells, and was the subject of a number of studies by Langen et al. [56-58]. They investigated the effects of TNF- $\alpha$ and IL- $1 \beta$ on differentiating and differentiated myoblasts [56]. To induce differentiation, myoblasts of murine skeletal muscle were prepared with a differentiation medium. Subsequently, TNF- $\alpha$ and IL-1 $\beta$ were added either immediately after the induction of differentiation or during a period of 5 days. The differentiation of TNF- $\alpha$-exposed cells was markedly inhibited, and furthermore this inhibition was dose dependent. In contrast, the effects on the fully differentiated cells were substantially different. While differentiating myoblasts contained significantly less protein when treated with TNF- $\alpha$ compared with controls, this was not found in the myotubes. Moreover, the decreases in the fast-twitch isotope of the myosin heavy chain as a result of TNF- $\alpha$ were dramatically higher in the myoblasts than in the myotubes. In line with these findings, Miller et al. [59] also found that the ability of TNF to affect muscle gene expression was greater in myoblasts than in myotubes. These results all indicate that it becomes more difficult for TNF- $\alpha$ to affect myogenic differentiation when myoblasts are in a later stage of differentiation.

To determine the relevance of the findings described above for COPD-associated muscle atrophy, an in vivo experiment was designed where control and TNF- $\alpha$ treated mice underwent a hind limb unloading program $[57,58]$. After 2 weeks of hind limb suspension, the mice received either placebo or a special TNF- $\alpha$ injection that induced chronic pulmonary inflammation. Following 5 days of reloading, which should induce muscle regeneration, the injected muscles were dissected. Analysis showed that there was no increase in specific muscle protein in

Respiration 2010;79:160-174 
the TNF- $\alpha$-treated animals, while there was in the controls. This indicates that the reloading did not induce (normal levels of) muscle regeneration in the mice with inflammation. Thus, these results confirm the in vitro findings mentioned above.

Although discussion of the exact ways in which TNF$\alpha$ causes impaired muscle regeneration is beyond the scope of this review, 2 interesting pathways are worth mentioning briefly. Firstly, there is the NF- $\kappa \mathrm{B}$ pathway. The cytokines TNF- $\alpha$ and IL- $1 \beta$ seem to block myogenic differentiation via activation of NF- $\kappa B$. Normally, NF$\kappa \mathrm{B}$ is bound to an inhibitory protein, but this protein is degraded by the action of these cytokines. In response, $\mathrm{NF}-\kappa \mathrm{B}$ moves to the nucleus, where it is involved in the synthesis of muscle protein. A second pathway via which inflammatory cytokines might be able to affect muscle regeneration and growth is through the inhibition of growth hormones [27, 60, 61]. Cytokines seem to reduce the sensitivity of the growth hormone receptors, which in turn causes decreased levels of insulin-like growth factor-1 (IGF-1), which is an important stimulant of protein synthesis in human myoblasts.

So, inflammatory cytokines seem to affect muscle regeneration, probably via defects in the differentiation process. However, there is no absolute consensus yet about the exact effects of cytokines, which may be due to the differing research conditions in the various studies. It is important that research into the effects of cytokines on muscle protein synthesis is extended, because this can contribute to the development of treatment options for people with COPD or other inflammatory diseases.

In conclusion, the muscle dysfunction in COPD seems to be caused by alterations in both the degradation and the synthesis rate of muscle protein. Several mechanisms are involved in these processes, as shown in figure 1 [62]. However, the exact mechanisms have not yet been completely elucidated, and this figure should be seen as hypothetical. In addition, it should be taken into account that the experiments described were all carried out in animals and that the results cannot be translated directly to the human situation. Interestingly, a human study on the effect of TNF- $\alpha$ on muscle protein turnover was performed very recently [63]. It was concluded that $4 \mathrm{~h}$ of acute infusion with TNF- $\alpha$ did not affect muscle protein breakdown or synthesis in 8 healthy young males. So, from this study it seems that TNF- $\alpha$ does not play a key role in muscle loss. However, to our knowledge this is the only study that has directly determined the effect of TNF$\alpha$ on muscle protein turnover in humans, and more research is necessary to investigate whether other doses or durations of infusion have an effect. For now, the evidence from animal studies that inflammatory cytokines do in some way affect muscle protein regulation, via both degradation and synthesis, is essential since within the scope of this review the key remaining question is whether the effects of these cytokines can be diminished with the help of a physical exercise program. In the following section, the effects of physical training are discussed.

\section{Inflammation and Exercise}

Whilst at first people with COPD were discouraged from exercising because of their airflow limitation, the benefits of physical training in these patients have now been conclusively demonstrated. Muscle strength and mechanical efficiency improve and dyspnea is reduced in patients who exercise regularly [64]. In addition, there is strong evidence that physical training improves the quality of life of people with COPD (for a systematic review, see Lacasse et al. [65]).

Interestingly, research in the last decade has focused on the benefits of exercise for inflammation in COPD. One theory states that exercise not only improves muscular dysfunction caused by disuse, but that it might diminish systemic inflammation as well [66]. Hence, this would be of great therapeutic interest. It is important within this discussion about the possible benefits of exercise on inflammation in COPD to discriminate between acute exercise and exercise training, since the responses seem to be different between these modalities.

\section{Acute Exercise and the Inflammatory Response in COPD}

Although exercise is generally associated with (improved) health, it has become clear that a single bout of exercise can induce an inflammatory response even in healthy people [67]. If the exercise is strenuous enough, several inflammatory cytokines appear to increase, causing catabolism, which would be a very negative side effect of exercise in COPD [68]. However, even though there seem to be many similarities between the inflammatory response after acute exercise and the inflammatory state in COPD, the 2 responses are not identical, as will be seen from the discussion below. The responses to acute exercise in healthy people and in patients with COPD, as well as in other patient groups, will be discussed.

Since a marathon run is likely to be sufficiently intense, the cytokine response in healthy subjects after a marathon run was investigated in different studies [67, 

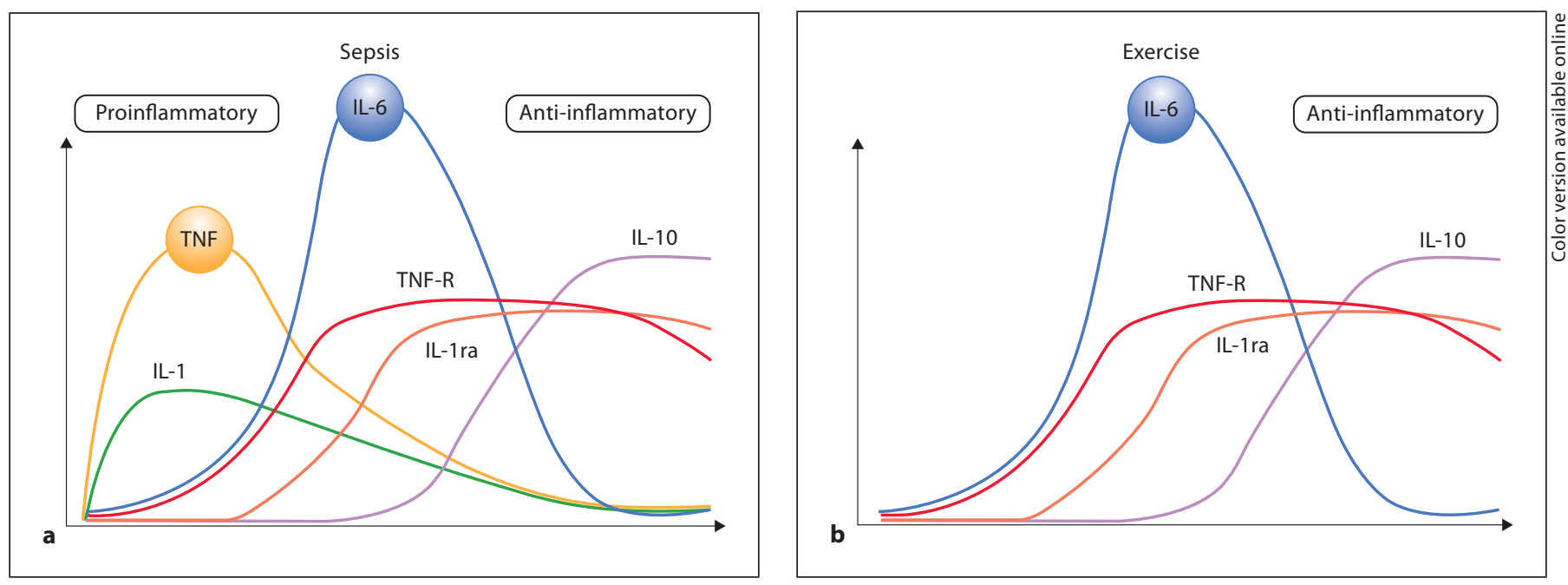

Fig. 2. The cytokine response in inflammation (sepsis; a) and with exercise (b). Whereas TNF has an important role in inflammation, its role in the response to exercise is uncertain. IL- 6 is markedly present in both responses. TNF-R = TNF receptor. Figure reprinted from Petersen and Pedersen [70], with permission.

69]. For instance, the results of Ostrowski et al. [67] showed that both TNF- $\alpha$ and IL-6 peaked immediately after a marathon race, with a 2.3- and 128-fold increase, respectively, compared to baseline levels. The anti-inflammatory cytokine IL-10 also peaked immediately (27fold increase), while IL-1 ra, which blocks the working of IL-1, peaked $1 \mathrm{~h}$ after the race (39-fold increase). These results were supported by separate findings of increased levels of IL-6 and IL-1ra after a 6-hour endurance run [69]. However, in this study, no increased levels of TNF$\alpha$ and IL-1 $\beta$, another proinflammatory cytokine, were found. Remarkably, while enormous increases in IL-6 have been consistently reported in the literature, the results regarding the response of TNF- $\alpha$ after exercise are ambiguous. Because these ambiguous results with regard to the TNF- $\alpha$ response to exercise are in contrast to the clear association between TNF- $\alpha$ and inflammation, some investigators state that this is an important difference between the inflammatory response after exercise and the inflammation seen in chronic inflammatory diseases such as COPD. Petersen and Pedersen [70] summarized the responses to both conditions (fig. 2), making clear the possible differences. As can be seen from the figure, IL- 6 is thought to be the most important response after exercise, while in inflammation there is a very important role for TNF- $\alpha$.

Interestingly, because IL- 6 is the most important mediator in the response to exercise and because exercise is normally associated with health, some scientists specu- late about a possible beneficial influence of IL-6 [70]. An important indication for the possible anti-inflammatory role of IL- 6 is the potential inhibitory effect of IL- 6 on TNF- $\alpha$. This was shown in a study where 8 healthy males took part in 3 different experimental conditions: a control condition in which they were resting; an experimental condition in which they cycled for $3 \mathrm{~h}$ at $75 \%$ of their $\mathrm{VO}_{2} \mathrm{max}$, and an rhIL- 6 condition in which they were infused with IL- 6 for $3 \mathrm{~h}$ [31]. In all 3 conditions, the subjects received an endotoxin that increased the plasma levels of TNF- $\alpha 2$ - to 3 -fold. While in the control condition the endotoxin infusion resulted in increased levels of TNF- $\alpha$, this increase was attenuated in the experimental and rhIL- 6 conditions, suggesting that physical exercise as well as IL- 6 infusion inhibits the production of TNF- $\alpha$ induced by endotoxin. So, it seems that IL- 6 plays an important role in the regulation of TNF- $\alpha$, which was confirmed by findings of increased levels of TNF- $\alpha$ in IL- 6 knockout mice [71]. However, the possibility that other mediators are involved in the regulation of TNF- $\alpha$ cannot be ruled out.

The possible inhibiting effect of IL- 6 on TNF- $\alpha$, a very important proinflammatory factor in COPD, sheds a new light on the enormous increase in IL- 6 induced by exercise, as this increase might actually be beneficial. Crucial at this point is whether the exercise-induced cytokine response in COPD is comparable to that in healthy people as described above. 
Several studies have investigated the response of IL- 6 to exercise in COPD patients, but the results are diverse. While one study found increases in IL- 6 after exercise [72], another did not [73], which is in contrast to the above-mentioned marked and consistently found increases in IL-6 in healthy people. More research should elucidate the pattern of IL- 6 during and following exercise, with particular attention paid to the possible beneficial effects of IL-6. In light of the results found in healthy people, it might be expected that exercise would increase IL- 6 in COPD patients as well.

The findings on the response of TNF- $\alpha$ to exercise in COPD patients are unfortunately the same as in the healthy population, i.e. inconsistent. Whereas van Helvoort et al. [72] were unable to find any increases in the levels of TNF- $\alpha$, IL-1ra and IL- 8 after exercise, another study did find increased levels of plasma TNF- $\alpha$ [73]. This latter finding was supported by the increased levels of TNF- $\alpha$ in patients with cystic fibrosis immediately after exercise [74]. Remarkably, an animal study indicated that exercise decreased levels of TNF- $\alpha$ [71]. The results of this study showed that in mice with overexpression of the TNF- $\alpha$ gene, these abnormal levels decreased to control levels after an exercise bout, suggesting that exercise might be able to normalize increased levels of TNF- $\alpha$. In summary, there is a great variety in the findings concerning the response to exercise of the important inflammatory cytokine TNF- $\alpha$.

Another marker of inflammation, leukocytosis, was found to be higher following maximal exercise in COPD subjects than in control subjects $[72,75]$. However, the number of leukocytes in the COPD patients was already higher at rest, and it was concluded that the exercise-induced inflammatory response was higher but not exaggerated in COPD. Nonetheless, the response of patients with COPD to submaximal exercise is less clear. While one study showed normal differences in the leukocytosis response between maximal and submaximal exercise in COPD patients [76], another was unable to find any differences [72]. The latter results might indicate an intensified response to submaximal exercise in COPD patients and thus frequent exposure to bursts of inflammation in response to submaximal activities in daily life. However, since the results are contradictory, it cannot be concluded yet whether submaximal exercise elicited a normal or an intensified response. However, the leukocytosis response following maximal exercise in COPD patients seems to be in proportion.

The oxidative response to exercise might provide additional information about the inflammatory response, since these responses seem to be closely related [72, 76]. Since inflammatory mediators seem to increase the level of ROS and reduce the amount of antioxidants, exercise might be accompanied by increased oxidative stress. Indeed, it seems that exercise decreases the activity of antioxidants against ROS (antioxidative capacity) in healthy people as well as in COPD patients [72]. Moreover, in COPD patients, but not in healthy subjects, ROS seem to increase after exercise [72, 77, 78], although one study failed to find changed ROS levels after exercise in COPD patients [73]. Taken together, the results on oxidative stress indicate that exercise might cause intensified oxidative stress after exercise in people with COPD.

In summary, there is no consensus on the inflammatory response to acute exercise in COPD, as the evidence regarding the inflammatory mediators IL- 6 , TNF- $\alpha$, leukocytosis and oxidative stress is contradictory. However, this is not very surprising given the several possible factors that might influence the results. The type, level and duration of exercise, for instance, seem to influence the outcome of the cytokine response. There is evidence that eccentric exercise elicits a more pronounced response of IL- 6 than concentric exercise, probably because of the muscle damage associated with eccentric exercise [79]. Moreover, the duration of exercise seems to be positively correlated with the amount of cytokine release [80], which might have caused differences between measurements in healthy people and in patient groups, because generally patients are fatigued earlier and thus exercise for a shorter period of time. In conclusion, there is a clear need for more research on this topic as more knowledge about the effects of exercise might give greater insight into some specific characteristics of COPD, such as the cytokine and oxidative responses.

\section{Exercise Training and the Inflammatory Response in COPD}

Although it remains unclear whether patients with COPD suffer or benefit from acute exercise with regard to systemic inflammation, this does not impact on research into the effects of long-term exercise. In patients with COPD but also in other patient groups with systemic inflammation, such knowledge might contribute to the development of a truly therapeutic treatment strategy.

Nowadays, almost all rehabilitation programs for patients with COPD include a physical exercise training component, and the physical benefits thereof have been demonstrated [65]. Of special interest are the improvements in muscle strength and muscle cross-sectional area [81], suggesting that exercise training has an anabolic ef- 
fect, which might be due to diminished inflammation, as inflammation seems to hinder anabolism and stimulate catabolism (see Systemic Inflammation and Muscle Dysfunction in COPD above). In fact, in healthy subjects there appears to be an association between the levels of regular exercise and inflammatory mediators, as the level of the inflammatory marker C-reactive protein (CRP) seemed to be lower in highly active people than in moderately active and inactive people $[82,83]$. However, because of the cross-sectional design of these studies, no definitive conclusion can be drawn about the causality of this relationship.

A large study with 652 healthy individuals participating in a 20 -week bicycle exercise training program might give more insight into this causality [84]. The results showed that people with high baseline CRP levels reduced their resting CRP level with training, while no changes were found in subjects with moderate and low baseline levels. This might indicate that people with high levels of inflammatory markers, as in COPD, benefit more from the potential anti-inflammatory effects of training than those who have lower inflammation levels to begin with. However, a control group was lacking in that study, so unfortunately it is possible that the observed changes were due to variables other than training. Mattusch et al. [85] did include a control group in their study on the effect of training for a marathon on CRP levels during rest and found decreased CRP levels in 10 out of 12 runners, while no changes were found in the control group. So, it seems that exercise training is able to reduce the levels of CRP in healthy people, at least in those with high baseline levels of CRP.

Although the resting level of another inflammatory mediator, IL- 6 , does not seem to be affected by training in healthy people, the increase in local IL-6 mRNA directly after a single exercise bout seems to be significantly diminished [86]. Before 10 weeks of knee extensor endurance training, the IL- 6 mRNA content increased 76fold after an exercise bout, while after the training period, this increase was reduced to only 8 -fold. Since the absolute workload after training increased to ensure the same relative workload before and after training, this change cannot be attributed to lower relative strain. The decreases in IL- 6 might be seen as a beneficial effect, since IL-6 is associated with inflammation. However, since the exact effect of IL- 6 remains unclear and TNF- $\alpha$ was not measured, these results are not conclusive. Remarkably, the local response of IL- 6 mRNA was not translated into a systemic effect as the circulating levels of IL- 6 did not change [86]. This was confirmed in another study which found no differences in circulating IL-6 in response to an exercise bout after 3 weeks of training [87]. So, this might indicate that training does not elicit the same responses at local and systemic levels. With regard to the last-mentioned study, it must be noted that they also failed to find any improvements in strength after the training, so it can be speculated that the training program was not appropriate (long enough) to elicit changes in cytokine levels either.

Within the field of inflammation and exercise training, elderly people form an interesting study population because aging is associated with low-grade inflammation [88]. Three months of strength training in frail elderly people resulted in increased muscle strength and decreased levels of muscle TNF- $\alpha$ protein levels (34\% decrease; $\mathrm{p}<0.01$ ) as well as muscle TNF- $\alpha$ mRNA levels (46\% decrease; $\mathrm{p}<0.01$ ) [89]. In addition, the synthesis rate of muscle protein increased by $83 \%$ and was negatively correlated with muscle TNF- $\alpha$ protein content $(\mathrm{r}=$ $-0.53, p=0.04)$. Hence, it can be speculated that strength training increases muscle protein synthesis via a reduction in local TNF- $\alpha$ levels. This effect might be limited to local cy tokine levels, as no effects of 12 weeks of strength training on circulating levels of TNF- $\alpha$ and IL- 6 were found in frail 90 -year-old subjects [90]. The lack of changes in systemic inflammatory levels might be explained by the specific character of the training programs, as only isolated strength was trained. Perhaps whole-body endurance training would have elicited systemic responses. However, these are only speculations because such a study has not yet been performed.

From the above it seems that the effect of exercise training on the inflammatory response in healthy (elderly) people has not yet been completely elucidated. Nonetheless, some studies indicate that people with high baseline levels of inflammatory markers are more likely to reduce these levels with training than people with low baseline levels. This would favor possible training-induced responses to inflammation in patients with chronic inflammation, as they have high baseline levels. Indeed, a study with CHF patients found impressive effects of a 6-month training program on local cytokine levels [66]. Daily cycling reduced the muscular levels of TNF- $\alpha$ by $38 \%$, IL- 6 by $42 \%$ and IL- $1 \beta$ by $48 \%$. Moreover, the amount of mRNA of the oxidative marker inducible NOS decreased by $52 \%$ after training. No changes were observed in the inactive control group. These findings clearly suggest that long-term training can have an antiinflammatory effect on local levels of inflammatory markers. Furthermore, decreased plasma levels of in- 


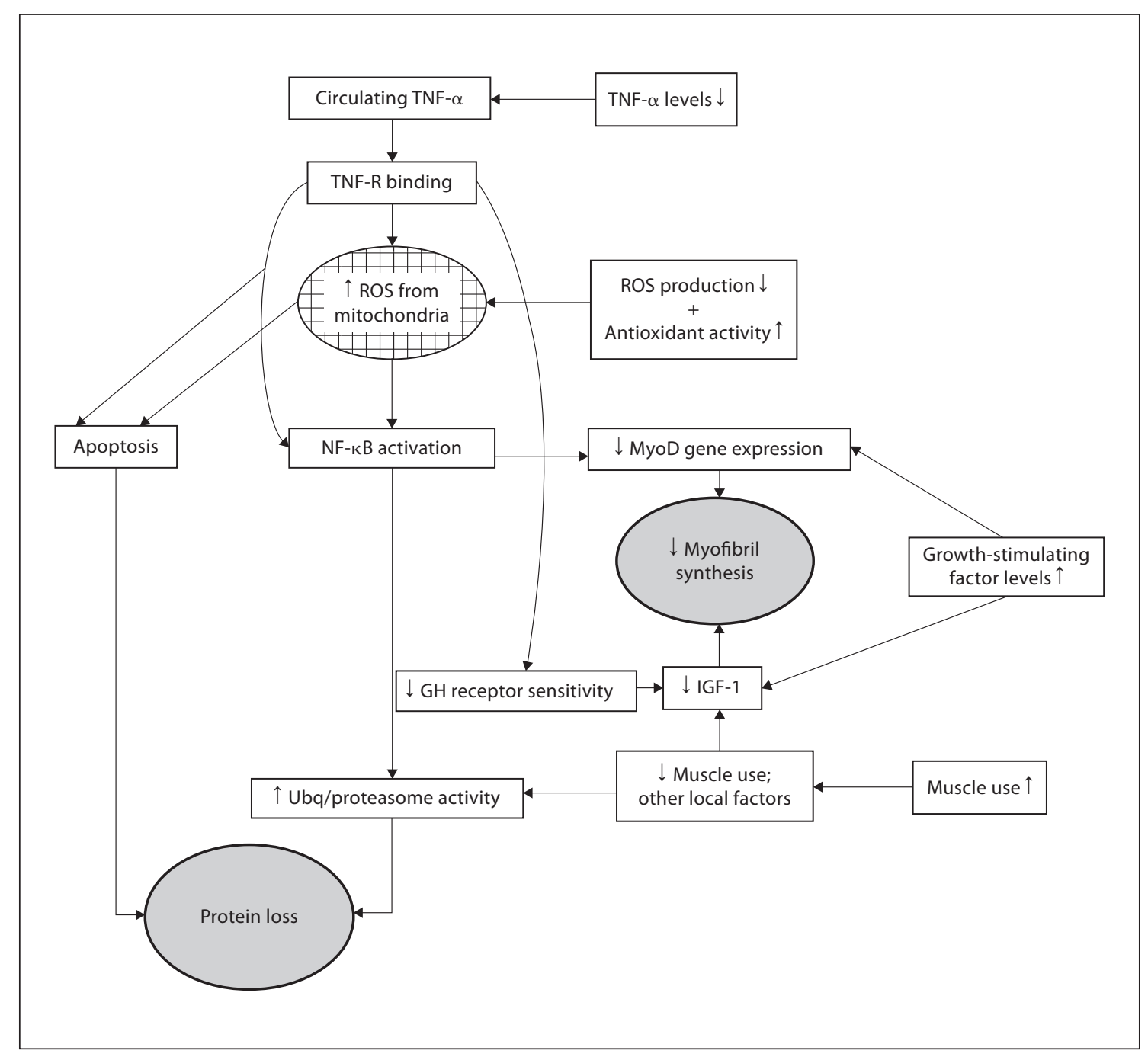

Fig. 3. The potential anti-inflammatory effect of exercise training. Exercise training might have an anti-inflammatory effect via reductions in TNF- $\alpha$ levels, reductions in ROS production, increased antioxidant activity, increased levels of the growth-stimulating factors myogenic differentiation factor D (MyoD) and IGF-1 and increased levels of muscle use. TNF-R = TNF receptor; Ubq = ubiquitin; GH = growth hormone. This figure was adapted from Sevenoaks and Stockley [62], with permission.

flammatory markers after a few months of physical training have been found, indicating reduced systemic inflammation in CHF patients after training [29, 91-93]. However, several studies failed to find any changes in plasma levels of TNF- $\alpha$, IL-6, IL-8 and CRP after training in patients with CHF [91-93]. So, although some studies showed clear beneficial effects of exercise training on inflammation in CHF, others failed to find any effect, making it impossible to draw a clear-cut conclusion. Nonetheless, it might be clear that exercise training is at least not harmful.
Unfortunately there are only a few studies on the possible anti-inflammatory effect of exercise training in patients with COPD, and the results are not impressive. For example, Bolton et al. [94] examined the effect of an 8week rehabilitation program with a physical as well as an educational component on systemic inflammation in COPD. While the program had a positive effect on body composition in the subjects with COPD, no changes were found in the levels of IL-6, TNF- $\alpha$ and TNF- $\alpha$ receptors after training. Also, an 8-week cycling program did not induce changes in plasma TNF- $\alpha$, IL- 6 and TNF receptor 
levels in patients with COPD or in the control group [73]. TNF- $\alpha$ mRNA did not change either. It should be noted that the latter study gave no information about the effectiveness of the training on physiological parameters, such as maximal oxygen uptake or power output, and therefore it remains unclear whether the training program was sufficient to elicit a training response at all. However, a study which found markedly improved fitness levels after a 10 -week training program in people with COPD also found no changes in the plasma levels of IL-6, TNF- $\alpha$ and CRP and in muscle mRNA TNF- $\alpha$ levels [95]. Nonetheless, these investigators did find marked increases in the levels of the growth-stimulating factors IGF-1, mechano growth factor and myogenic differentiation factor D. Since growth factors seem to be inhibited by inflammatory cytokines and since these levels were stable, this might be a surprising finding. The researchers gave as a possible explanation that the training program elicits such a stimulus that the negative effects of the cytokines are exceeded by the increase in IGF-1, mechano growth factor and myogenic differentiation factor $\mathrm{D}$ [95]. This is a positive effect of training, as the levels of these growth factors are often decreased in patients who suffer from systemic inflammation [61]. In addition, physical training was found to reduce ROS-induced DNA damage in COPD patients [77], another beneficial effect which might also be influenced by inflammation. In figure 3, some potential anti-inflammatory effects of exercise training are presented. However, these effects are speculative and the figure should be interpreted with caution.

In conclusion, exercise training seems to have beneficial effects on muscle function and other physical parameters in COPD, despite the absence of any proven decrease in inflammatory mediators. This lack of decreased levels of cytokines after several weeks or months of exercise training might be partly caused by the differences in responsiveness to training seen in individuals with COPD $[96,97]$. Indeed, patients with, for example, less ventilatory limitation seem to benefit more from exercise training [97]. Whether such a differentiation is also seen in the inflammatory response should be investigated in further research. It is conceivable that different levels of inflammatory cytokines in patients with COPD elicit different training responses with regard to these cytokine levels. Future studies should take this parameter into account because this might uncover training effects in certain subgroups of COPD patients.

The intensity of the training programs could also have influenced the results in the studies of exercise training in COPD patients. In the study with CHF patients that showed the largest anti-inflammatory effect of training, the participants cycled 4-6 times every day for a short 10 -min period. All the other studies prescribed longer and less frequent exercise periods. Moreover, the successful training program had a total duration of 6 months, whereas the others were mostly between 2 and 3 months. So, this might suggest that short, frequent exercising over a longer period of time is more likely to elicit anti-inflammatory responses than long, less frequent exercising over a shorter period of time. However, these are only speculations based on one successful study, and more research is absolutely essential to confirm this.

\section{Conclusion and Recommendations}

The high levels of circulating inflammatory cytokines in COPD seem to cause muscle dysfunction through an imbalance between muscle protein synthesis and degradation. Since exercise seems to have a positive effect on the protein balance, it was hypothesized that this might be caused by diminished levels of inflammatory cytokines. Although an acute bout of exercise elicits an inflammatory response in most people, long-term exercise training actually seems to reduce the levels of inflammatory cytokines in healthy subjects and CHF patients. However, the evidence is not strong and the results in COPD patients are particularly contradictory. These variable findings might be partly due to the research designs, which differ in many points among the studies. The intensity, duration, frequency and type of exercise might all influence the results. In future studies, these parameters should be optimized to attain conclusive results. In addition, it should be taken into account that the responsiveness to training might differ among patients. Besides the differences in physiological parameters, the possible heterogeneity regarding inflammatory cytokine levels might have influenced the responsiveness to training.

In conclusion, although exercise training has obvious physical benefits in COPD, an anti-inflammatory effect of training has not (yet) been proven in this patient group. However, the research is scarce and future studies with more finely tuned training programs might give definitive answers. 


\section{References}

- 1 Buist AS, McBurnie MA, Vollmer WM, Gillespie S, Burney P, Mannino DM, et al: International variation in the prevalence of COPD (the BOLD Study): a population-based prevalence study. Lancet 2007;370:741-750.

$\checkmark 2$ Jones PW: Issues concerning health-related quality of life in COPD. Chest 1995;107: 187S-193S

-3 Killian KJ, Leblanc P, Martin DH, Summers E, Jones NL, Campbell EJ: Exercise capacity and ventilatory, circulatory, and symptom limitation in patients with chronic airflow limitation. Am Rev Respir Dis 1992;146: 935-940.

4 Debigare R, Cote CH, Maltais F: Peripheral muscle wasting in chronic obstructive pulmonary disease. Clinical relevance and mechanisms. Am J Respir Crit Care Med 2001;164:1712-1717.

-5 Zanotti E, Felicetti G, Maini M, Fracchia C: Peripheral muscle strength training in bedbound patients with COPD receiving mechanical ventilation: effect of electrical stimulation. Chest 2003;124:292-296.

-6 Bernard S, Leblanc P, Whittom F, Carrier G, Jobin J, Belleau R, et al: Peripheral muscle weakness in patients with chronic obstructive pulmonary disease. Am J Respir Crit Care Med 1998;158:629-634.

$\checkmark 7$ O'Shea SD, Taylor NF, Paratz J: Peripheral muscle strength training in COPD: a systematic review. Chest 2004;126:903-914.

-8 Agusti AG, Noguera A, Sauleda J, Sala E, Pons J, Busquets X: Systemic effects of chronic obstructive pulmonary disease. Eur Respir J 2003;21:347-360.

$\checkmark$ Casaburi R: Skeletal muscle function in COPD. Chest 2000;117:267S-271S.

10 Wouters EF: Chronic obstructive pulmonary disease. 5. Systemic effects of COPD. Thorax 2002;57:1067-1070.

-11 Decramer M, Lacquet LM, Fagard R, Rogiers $\mathrm{P}$ : Corticosteroids contribute to muscle weakness in chronic airflow obstruction. Am J Respir Crit Care Med 1994;150:11-16.

12 Gosselink R, Troosters T, Decramer M: Peripheral muscle weakness contributes to exercise limitation in COPD. Am J Respir Crit Care Med 1996;153:976-980.

13 Hamilton AL, Killian KJ, Summers E, Jones NL: Muscle strength, symptom intensity, and exercise capacity in patients with cardiorespiratory disorders. Am J Respir Crit Care Med 1995;152:2021-2031.

14 Serres I, Gautier V, Varray A, Prefaut C: Impaired skeletal muscle endurance related to physical inactivity and altered lung function in COPD patients. Chest 1998;113:900-905.

15 Gosker HR, Kubat B, Schaart G, van der Vusse GJ, Wouters EF, Schols AM: Myopathological features in skeletal muscle of patients with chronic obstructive pulmonary disease. Eur Respir J 2003;22:280-285.
16 Wuyam B, Payen JF, Levy P, Bensaidane H, Reutenauer H, Le Bas JF, et al: Metabolism and aerobic capacity of skeletal muscle in chronic respiratory failure related to chronic obstructive pulmonary disease. Eur Respir J 1992;5:157-162.

17 Jakobsson P, Jorfeldt L, Brundin A: Skeletal muscle metabolites and fibre types in patients with advanced chronic obstructive pulmonary disease (COPD), with and without chronic respiratory failure. Eur Respir J 1990;3:192-196.

-18 Satta A, Migliori GB, Spanevello A, Neri M, Bottinelli R, Canepari M, et al: Fibre types in skeletal muscles of chronic obstructive pulmonary disease patients related to respiratory function and exercise tolerance. Eur Respir J 1997;10:2853-2860.

19 Gosker HR, Wouters EF, van der Vusse GJ, Schols AM: Skeletal muscle dysfunction in chronic obstructive pulmonary disease and chronic heart failure: underlying mechanisms and therapy perspectives. Am J Clin Nutr 2000;71:1033-1047.

20 Jakobsson P, Jorfeldt L, Henriksson J: Metabolic enzyme activity in the quadriceps femoris muscle in patients with severe chronic obstructive pulmonary disease. Am J Respir Crit Care Med 1995;151:374-377.

21 Maltais F, Simard AA, Simard C, Jobin J, Desgagnes P, Leblanc P: Oxidative capacity of the skeletal muscle and lactic acid kinetics during exercise in normal subjects and in patients with COPD. Am J Respir Crit Care Med 1996;153:288-293.

22 Moller P, Hellstrom K, Hermansson IL: Myoglobin content in leg skeletal muscle in patients with chronic obstructive lung disease. Respiration 1984;45:35-38.

-23 Howald H, Pette D, Simoneau JA, Uber A, Hoppeler H, Cerretelli P: Effects of chronic hypoxia on muscle enzyme activities. Int J Sports Med 1990;11:S10-S14.

-24 Hoppeler H, Kleinert E, Schlegel C, Claassen H, Howald H, Kayar SR, et al: Morphological adaptations of human skeletal muscle to chronic hypoxia. Int J Sports Med 1990; 11(suppl 1):S3-S9.

25 Payen JF, Wuyam B, Levy P, Reutenauer H, Stieglitz P, Paramelle B, et al: Muscular metabolism during oxygen supplementation in patients with chronic hypoxemia. Am Rev Respir Dis 1993;147:592-598.

-26 Llovera M, Garcia-Martinez C, Agell N, Lopez-Soriano FJ, Argiles JM: TNF can directly induce the expression of ubiquitin-dependent proteolytic system in rat soleus muscles. Biochem Biophys Res Commun 1997;230: 238-241.
27 Remels AH, Gosker HR, van der Velden J, Langen RC, Schols AM: Systemic inflammation and skeletal muscle dysfunction in chronic obstructive pulmonary disease: state of the art and novel insights in regulation of muscle plasticity. Clin Chest Med 2007;28: 537-552, vi

28 Broekhuizen R, Wouters EF, Creutzberg EC, Schols AM: Raised CRP levels mark metabolic and functional impairment in advanced COPD. Thorax 2006;61:17-22.

29 Adamopoulos S, Parissis J, Kroupis C, Georgiadis M, Karatzas D, Karavolias G, et al: Physical training reduces peripheral markers of inflammation in patients with chronic heart failure. Eur Heart J 2001;22:791-797.

30 Yende S, Waterer GW, Tolley EA, Newman $A B$, Bauer DC, Taaffe DR, et al: Inflammatory markers are associated with ventilatory limitation and muscle dysfunction in obstructive lung disease in well functioning elderly subjects. Thorax 2006;61:10-16.

31 Starkie R, Ostrowski SR, Jauffred S, Febbraio M, Pedersen BK: Exercise and IL-6 infusion inhibit endotoxin-induced TNF-alpha production in humans. FASEB J 2003;17:884886.

32 van Eeden SF, Sin DD: Chronic obstructive pulmonary disease: a chronic systemic inflammatory disease. Respiration 2008;75: 224-238.

33 Gan WQ, Man SF, Senthilselvan A, Sin DD: Association between chronic obstructive pulmonary disease and systemic inflammation: a systematic review and a meta-analysis. Thorax 2004;59:574-580.

>34 Piehl-Aulin K, Jones I, Lindvall B, Magnuson A, Abdel-Halim SM: Increased serum inflammatory markers in the absence of clinical and skeletal muscle inflammation in patients with chronic obstructive pulmonary disease. Respiration 2009;78:191-196.

- 35 Di Francia M, Barbier D, Mege JL, Orehek J: Tumor necrosis factor-alpha levels and weight loss in chronic obstructive pulmonary disease. Am J Respir Crit Care Med 1994;150:1453-1455.

-36 Pitsiou G, Kyriazis G, Hatzizisi O, Argyropoulou P, Mavrofridis E, Patakas D: Tumor necrosis factor-alpha serum levels, weight loss and tissue oxygenation in chronic obstructive pulmonary disease. Respir Med 2002;96:594-598.

37 Cannon JG: Exercise and resistance to infection. J Appl Physiol 1993;74:973-981.

- 38 Eid AA, Ionescu AA, Nixon LS, Lewis-Jenkins V, Matthews SB, Griffiths TL, et al: Inflammatory response and body composition in chronic obstructive pulmonary disease. Am J Respir Crit Care Med 2001;164:14141418 . 
\$3 Fong Y, Moldawer LL, Marano M, Wei H, Barber A, Manogue K, et al: Cachectin/TNF or IL-1 alpha induces cachexia with redistribution of body proteins. Am J Physiol 1989; 256:R659-R665.

-40 Moldawer LL, Svaninger G, Gelin J, Lundholm KG: Interleukin 1 and tumor necrosis factor do not regulate protein balance in skeletal muscle. Am J Physiol 1987;253: C766-C773.

-41 Kettelhut IC, Goldberg AL: Tumor necrosis factor can induce fever in rats without activating protein breakdown in muscle or lipolysis in adipose tissue. J Clin Invest 1988;81: 1384-1389.

-42 Oliff A, Defeo-Jones D, Boyer M, Martinez D, Kiefer D, Vuocolo G, Wolfe A, Socher SH: Tumors secreting human TNF/cachectin induce cachexia in mice. Cell 1987;50:555563.

-43 Li YP, Schwartz RJ, Waddell ID, Holloway BR, Reid MB: Skeletal muscle myocytes undergo protein loss and reactive oxygen-mediated NF-kappaB activation in response to tumor necrosis factor alpha. FASEB J 1998; 12:871-880.

$\checkmark 44$ Cai D, Frantz JD, Tawa NE Jr, Melendez PA, Oh BC, Lidov HG, et al: IKKbeta/NF-kappaB activation causes severe muscle wasting in mice. Cell 2004;119:285-298.

-45 Flores EA, Bistrian BR, Pomposelli JJ, Dinarello CA, Blackburn GL, Istfan NW: Infusion of tumor necrosis factor/cachectin promotes muscle catabolism in the rat. A synergistic effect with interleukin 1. J Clin Invest 1989;83:1614-1622.

46 Llovera M, Lopez-Soriano FJ, Argiles JM: Effects of tumor necrosis factor-alpha on muscle-protein turnover in female Wistar rats. J Natl Cancer Inst 1993;85:1334-1339.

-47 Meier B, Radeke HH, Selle S, Younes M, Sies $\mathrm{H}$, Resch K, et al: Human fibroblasts release reactive oxygen species in response to interleukin-1 or tumour necrosis factor-alpha. Biochem J 1989;263:539-545.

-48 Buck M, Chojkier M: Muscle wasting and dedifferentiation induced by oxidative stress in a murine model of cachexia is prevented by inhibitors of nitric oxide synthesis and antioxidants. EMBO J 1996;15:1753-1765.

-49 Vary TC, Owens EL, Beers JK, Verner K, Cooney RN: Sepsis inhibits synthesis of myofibrillar and sarcoplasmic proteins: modulation by interleukin-1 receptor antagonist. Shock 1996;6:13-18.

50 Cooney R, Owens E, Jurasinski C, Gray K, Vannice J, Vary T: Interleukin-1 receptor antagonist prevents sepsis-induced inhibition of protein synthesis. Am J Physiol 1994;267: E636-E641.

-51 Vary TC, Kimball SR: Sepsis-induced changes in protein synthesis: differential effects on fast- and slow-twitch muscles. Am J Physiol 1992;262:C1513-C1519.
52 Garcia-Martinez C, Lopez-Soriano FJ, Argiles JM: Acute treatment with tumour necrosis factor-alpha induces changes in protein metabolism in rat skeletal muscle. Mol Cell Biochem 1993;125:11-18.

53 Muthny T, Kovarik M, Sispera L, Tilser I, Holecek M: Protein metabolism in slow- and fast-twitch skeletal muscle during turpentine-induced inflammation. Int J Exp Pathol 2008;89:64-71.

54 Millward DJ, Garlick PJ, James WP, Nnanyelugo DO, Ryatt JS: Relationship between protein synthesis and RNA content in skeletal muscle. Nature 1973;241:204-205.

55 Rannels SR, Jefferson LS: Effects of glucocorticoids on muscle protein turnover in perfused rat hemicorpus. Am J Physiol 1980; 238:E564-E572.

56 Langen RC, Schols AM, Kelders MC, Wouters EF, Janssen-Heininger YM: Inflammatory cytokines inhibit myogenic differentiation through activation of nuclear factor-kappaB. FASEB J 2001;15:1169-1180.

57 Langen RC, van der Velden JL, Schols AM, Kelders MC, Wouters EF, Janssen-Heininger YM: Tumor necrosis factor-alpha inhibits myogenic differentiation through MyoD protein destabilization. FASEB J 2004;18: 227-237.

58 Langen RC, Schols AM, Kelders MC, van der Velden JL, Wouters EF, Janssen-Heininger YM: Muscle wasting and impaired muscle regeneration in a murine model of chronic pulmonary inflammation. Am J Respir Cell Mol Biol 2006;35:689-696.

59 Miller SC, Ito H, Blau HM, Torti FM: Tumor necrosis factor inhibits human myogenesis in vitro. Mol Cell Biol 1988;8:2295-2301.

-60 Broussard SR, McCusker RH, Novakofski JE, Strle K, Shen WH, Johnson RW, et al: Cytokine-hormone interactions: tumor necrosis factor alpha impairs biologic activity and downstream activation signals of the insulin-like growth factor I receptor in myoblasts. Endocrinology 2003;144:2988-2996.

61 Thissen JP: How proinflammatory cytokines may impair growth and cause muscle wasting. Horm Res 2007;67:64-70.

62 Sevenoaks MJ, Stockley RA: Chronic obstructive pulmonary sisease, inflammation and co-morbidity - a common inflammatory phenotype? Respir Res 2006;7:70.

63 Petersen AM, Plomgaard P, Fischer CP, Ibfelt T, Pedersen BK, van Hall G: Acute moderate elevation of TNF-alpha does not affect systemic and skeletal muscle protein turnover in healthy humans. J Clin Endocrinol Metab 2009;94:294-299.

64 Garrod R, Ansley P, Canavan J, Jewell A: Exercise and the inflammatory response in chronic obstructive pulmonary disease (COPD) - does training confer anti-inflammatory properties in COPD? Med Hypotheses 2007;68:291-298.
65 Lacasse Y, Maltais F, Goldstein RS: Pulmonary rehabilitation: an integral part of the long-term management of COPD. Swiss Med Wkly 2004;134:601-605.

-66 Gielen S, Adams V, Mobius-Winkler S, Linke A, Erbs S, Yu J, et al: Anti-inflammatory effects of exercise training in the skeletal muscle of patients with chronic heart failure. J Am Coll Cardiol 2003;42:861-868.

67 Ostrowski K, Rohde T, Asp S, Schjerling P, Pedersen BK: Pro- and anti-inflammatory cytokine balance in strenuous exercise in humans. J Physiol 1999;515:287-291.

68 van Helvoort HA, Heijdra YF, Dekhuijzen $\mathrm{PN}$ : Systemic immunological response to exercise in patients with chronic obstructive pulmonary disease: what does it mean? Respiration 2006;73:255-264.

69 Drenth JP, Van Uum SH, Van DM, Pesman GJ, van der Ven-Jongekrijg J, Van der Meer JW: Endurance run increases circulating IL6 and IL-1ra but downregulates ex vivo TNFalpha and IL-1 beta production. J Appl Physiol 1995;79:1497-1503.

70 Petersen AM, Pedersen BK: The anti-inflammatory effect of exercise. J Appl Physiol 2005;98:1154-1162.

77 Keller C, Keller P, Giralt M, Hidalgo J, Pedersen BK: Exercise normalises overexpression of TNF-alpha in knockout mice. Biochem Biophys Res Commun 2004;321: 179-182.

72 van Helvoort HA, Heijdra YF, Thijs HM, Vina J, Wanten GJ, Dekhuijzen PN: Exerciseinduced systemic effects in muscle-wasted patients with COPD. Med Sci Sports Exerc 2006;38:1543-1552.

73 Rabinovich RA, Figueras M, Ardite E, Carbo N, Troosters T, Filella X, et al: Increased tumour necrosis factor-alpha plasma levels during moderate-intensity exercise in COPD patients. Eur Respir J 2003;21:789-794.

74 Tirakitsoontorn P, Nussbaum E, Moser C, Hill M, Cooper DM: Fitness, acute exercise, and anabolic and catabolic mediators in cystic fibrosis. Am J Respir Crit Care Med 2001; 164:1432-1437.

75 van Helvoort HA, van de Pol MH, Heijdra YF, Dekhuijzen PN: Systemic inflammatory response to exhaustive exercise in patients with chronic obstructive pulmonary disease. Respir Med 2005;99:1555-1567.

76 van Helvoort HA, Heijdra YF, de Boer RCC, Swinkels A, Thijs HMH, Dekhuijzen PN: Six-minute walking-induced systemic inflammation and oxidative stress in musclewasted COPD patients. Chest 2007;131:439445.

77 Mercken EM, Hageman GJ, Schols AM, Akkermans MA, Bast A, Wouters EF: Rehabilitation decreases exercise-induced oxidative stress in chronic obstructive pulmonary disease. Am J Respir Crit Care Med 2005;172: 994-1001. 
78 Couillard A, Maltais F, Saey D, Debigare R, Michaud A, Koechlin C, et al: Exercise-induced quadriceps oxidative stress and peripheral muscle dysfunction in patients with chronic obstructive pulmonary disease. Am J Respir Crit Care Med 2003;167:1664-1669.

-79 Bruunsgaard H, Galbo H, Halkjaer-Kristensen J, Johansen TL, MacLean DA, Pedersen BK: Exercise-induced increase in serum interleukin- 6 in humans is related to muscle damage. J Physiol 1997;499:833-841.

-80 Pedersen BK, Ostrowski K, Rohde T, Bruunsgaard $\mathrm{H}$ : The cytokine response to strenuous exercise. Can J Physiol Pharmacol 1998; 76:505-511.

-81 Bernard S, Whittom F, Leblanc P, Jobin J, Belleau R, Berube C, et al: Aerobic and strength training in patients with chronic obstructive pulmonary disease. Am J Respir Crit Care Med 1999;159:896-901.

82 Abramson JL, Vaccarino V: Relationship between physical activity and inflammation among apparently healthy middle-aged and older US adults. Arch Intern Med 2002;162: 1286-1292.

-83 Geffken DF, Cushman M, Burke GL, Polak JF, Sakkinen PA, Tracy RP: Association between physical activity and markers of inflammation in a healthy elderly population. Am J Epidemiol 2001;153:242-250.

-84 Lakka TA, Lakka HM, Rankinen T, Leon AS, Rao DC, Skinner JS, et al: Effect of exercise training on plasma levels of C-reactive protein in healthy adults: the HERITAGE Family Study. Eur Heart J 2005;26:2018-2025.
85 Mattusch F, Dufaux B, Heine O, Mertens I, Rost R: Reduction of the plasma concentration of C-reactive protein following nine months of endurance training. Int J Sports Med 2000;21:21-24.

86 Fischer CP, Plomgaard P, Hansen AK, Pilegaard $\mathrm{H}$, Saltin B, Pedersen BK: Endurance training reduces the contraction-induced interleukin-6 mRNA expression in human skeletal muscle. Am J Physiol Endocrinol Metab 2004;287:E1189-E1194.

87 Croisier JL, Camus G, Venneman I, by-Dupont G, Juchmes-Ferir A, Lamy M, et al: Effects of training on exercise-induced muscle damage and interleukin 6 production. Muscle Nerve 1999;22:208-212.

88 Hager K, Machein U, Krieger S, Platt D, Seefried G, Bauer J: Interleukin-6 and selected plasma proteins in healthy persons of different ages. Neurobiol Aging 1994;15:771-772.

89 Greiwe JS, Cheng B, Rubin DC, Yarasheski KE, Semenkovich CF: Resistance exercise decreases skeletal muscle tumor necrosis factor alpha in frail elderly humans. FASEB J 2001;15:475-482.

90 Bruunsgaard H, Bjerregaard E, Schroll M, Pedersen BK: Muscle strength after resistance training is inversely correlated with baseline levels of soluble tumor necrosis factor receptors in the oldest old. J Am Geriatr Soc 2004;52:237-241.

91 Larsen AI, Aukrust P, Aarsland T, Dickstein $\mathrm{K}$ : Effect of aerobic exercise training on plasma levels of tumor necrosis factor alpha in patients with heart failure. Am J Cardiol 2001;88:805-808
92 Conraads VM, Beckers P, Bosmans J, De Clerck LS, Stevens WJ, Vrints CJ, et al: Combined endurance/resistance training reduces plasma TNF-alpha receptor levels in patients with chronic heart failure and coronary artery disease. Eur Heart J 2002;23:18541860.

$\checkmark 93$ Laoutaris ID, Dritsas A, Brown MD, Manginas A, Kallistratos MS, Degiannis D, et al: Immune response to inspiratory muscle training in patients with chronic heart failure. Eur J Cardiovasc Prev Rehabil 2007;14: 679-685.

$\checkmark 94$ Bolton CE, Broekhuizen R, Ionescu AA, Nixon LS, Wouters EF, Shale DJ, et al: Cellular protein breakdown and systemic inflammation are unaffected by pulmonary rehabilitation in COPD. Thorax 2007;62:109-114.

$>95$ Vogiatzis I, Stratakos G, Simoes DC, Terzis G, Georgiadou O, Roussos C, et al: Effects of rehabilitative exercise on peripheral muscle TNFalpha, IL-6, IGF-I and MyoD expression in patients with COPD. Thorax 2007;62: 950-956.

-96 Spruit MA, Gosselink R, Troosters T, Kasran A, Van VM, Decramer M: Low-grade systemic inflammation and the response to exercise training in patients with advanced COPD. Chest 2005; 128:3183-3190.

$\checkmark 97$ Troosters T, Gosselink R, Decramer M: Exercise training in COPD: how to distinguish responders from nonresponders. J Cardiopulm Rehabil 2001;21:10-17. 